\title{
La adveración sacramental del testamento en la Cataluña altomedieval ${ }^{1}$
}

\author{
Antoni M. Udina i Abelló \\ Universitat Autònoma de Barcelona. \\ Departament de Ciències de l'Antiguitat i de l'Edat Mitjana. \\ 08193 Bellaterra (Barcelona). Spain
}

\section{Resumen}

La adveración sacramental, incorrectamente denominada testamento sacramental, es una tipologia documental de una forma testamentaria relacionada con testamentos orales y escritos, muy interesante para conocer diferentes aspectos sobre la muerte. Testimoniada en el Liber Indiciorum, fue incorporada al privilegio de Barcelona de 1283 y a las "Constitucions i alures drets de Catalunya». Pero sufrió una evolución, con diversos cambios sobre todo en el siglo XII, y a medida que el derecho visigodo fue desapareciendo sustituido por el derecho común se hizo cada vez más rara.

Abstract. The adveración sacramental of testament in medieval's Catalonia

Adveracion sacramentah, incorrectly named testamento sacramental, is a documentary typology of a testamentary norm related to oral and written wills, and very interesting to know some different aspects about death. Attested it in the Liber Iudiciorwm, it was incorporated into Barcelona's privilegy of 1283 and aConstitucions $i$ altres drets de Catalunyaw. But this underwent an evolution with significant changes overcoat in the 12 th century, and in proportion as Visigothic law was vanishing and Common law was prevailing, this one became rare.

\section{Sumari}

1. Los precedentes 4. Las circunstancias de la muerte

2. La muestra documental del testador

3. Requisitos legales

Conclusiones

Apéndice documental

1. El presente artículo es una revisión y actualización de la comunicación presentada en el Congreso de la sSocieté Jean Bodin celebrado en mayo de 1990 en Budapest, sobre «L'acte à cause de morto. 
Una de las formas testamentarias medievales que se dan en el territorio que constituirá Cataluña es la adveración sacramental del testamento. Se trata del juramento que hacen dos o más testigos sobre un altar y en presencia del juez, de haber visto y oído cómo el testador expresó, por escrito u oralmente, su última voluntad. A nuestro juicio la denominación de testamento sacramental que habitualmente recibe no es apropiada, ya que el acto testamentario propiamente dicho es anterior a la elaboración del documento que refleja la mençionada ceremonia del juramento, ceremonia que además también se utiliza en otros casos como la "reparatio scripturae» o en pleitos y juicios.

Este tipo documental nos permite conocer, por una parte, testamentos orales, que de otra forma no habrían llegado hasta nosotros, además de otros interesantes aspectos relativos a la causa, lugar y fecha de la muerte de los testadores, así como, naturalmente, el contenido de las disposiciones testamentarias. Bastier, en su estudio sobre algunos testamentos catalanes publicados, trató de la cuestión y fue el primero en advertir de la incongruencia del término testamento sacramenta ${ }^{2}$. A pesar de ello, en la práctica, la denominación de testamento sacramental fue recogida en el privilegio otorgado a la ciudad de Barcelona por Pedro el Grande en 1283, conocido con el nombre de Recognoverunt proceres, que posteriormente se integró en las Constitucions $i$ altres drets de Catalunya en el capítulo 48 con el título: "Testament iurat que hom diu sagramental" y que en la traducción catalana posterior define de este modo: "Encara que es custuma que si nengu fara testament en presencia de testimonis, en terra en mar, en qualque loc sia, ab escrit o menys descrit, manifestara de paraula ho ab escrit, sens notari, que vayla aquella darrera volentat ho testament, pus quels testimonis qui seran a aquella darrera volentat ho testament, ebffre . vi. meses pus que seran a Barcelona, juren en la esgleya de sent Just sobrel altar de sent Feliu martir, preent lo notari qui aytals testaments ffa e enaltres persones, que aquells testimonis axi veeren e hohiren escriure e dir axi com en aquella escriptura es contengut, ho darrera volentat dita de paraula daquell testador, e que aytals testaments son appellats sagramentals".

El tema ha sido objeto de atención por mi parte en dos ocasiones anteriores: una primera aproximación puede verse en mi obra sobre la sucesión testada en Cataluña desde final del siglo Ix hasta el año 1025. Con posterioridad volví específicamente sobre este tipo documental en la publicación y comentario en la obra colectiva "Documents jurídics de la historia de Catalunya ${ }^{3}$. La abundante documentación conservada en los archivos catalanes nos ha permitido alargar la cronología y, centrándonos exclusivamente en la forma testamentaria aludida, elaborar el presente trabajo sobre una muestra representativa de quinientos documentos que constituyen sendas publicaciones o

2. Bastier, J. (1973). „Le testament en Catalogne du IX au XII siècle: une survivance wisigothiques. Revue Historique du Droit Français et Etranger, p. 374-417.

3. UDINA, A. (1984). La successió testada a la Catalunya altomedieval. Barcelona: Fundació Noguera. Especialmente p. 51-58. UDINA, A. (1991). Testament sacramental, «Documents Jurídics de la Història de Catalunya». Generalitat de Catalunya, p. 43-50. 
adveraciones sacramentales, comprendidos entre los años 961 y 1209 y que se refieren a Cataluña.

Nos ha interesado en concreto resaltar el aspecto formal del tipo documental estudiado y hemos prescindido del estudio del contenido de los testamentos que son objeto de publicación o adveración, ya que hubiera alargado en demasía el trabajo y hubiera resultado desproporcionado con la temática concreta que nos hemos propuesto tratar.

\section{Los precedentes}

La pervivencia en la Cataluña altomedieval del derecho visigodo es un fenómeno bien conocido y especialmente estudiado en los últimos veinticinco años tanto desde el punto de vista propiamente jurídico, como en el aspecto cultural ${ }^{4}$.

En el caso que nos ocupa la regulación de la adveración sacramental aparece claramente fijada en el Liber ludiciorum cuando se refiere a las cuatro formas testamentarias que reconoce: tres de ellas escritas y la cuarta oral; las tres primeras se diferencian en la presencia o no de las firmas de testador $y$ testigos, conjuntamente o alternativamente 5 . En la documentación estudiada vemos reflejadas las distintas formas testamentarias visigodas. No se trata exclusivamente de la cuarta forma, la oral, la que por su naturaleza exigia una adveración posterior, sino que también se hace referencia al "primus, secundus, tercius ordo.... Examinemos con mayor detalle la formulación legal visigoda al respecto. «Scripta voluntas defuncti ante sex menses coram guolibet sacerdote vel testibus publicetur» dice la Lex refiriéndose a la forma escrita del testamento, y dos artículos antes regula la adveración del testamento oral en estos términos: «Illa vero voluntas defuncti quae iuxta quarti ordinis modum verbis tantummodo coram probatione promulgata patuerit, quae instante quocumque periculo conscribi nequiverit, et tamen ab eo qui moritur iussa fuerit alligari, tunc robur plenissimum obtinebit, si testes ipsi, qui hoc audierint et rogati a conditori extiterint infra sex mensium spatium, hoc quod iniunctum habuerint sua coram iudice iuratione confirment ciusdemgue iuramenti conditionem tam sua quam testium manum corroborento ${ }^{6}$. La inexistencia de notario, dotado con fe pública, provoca la necesidad de homologar el testamento ante una autoridad y bajo jura-

4. IGLESIA, A. (1980), "La creación histórica del derecho en Cataluñav. AHDE. KIENAST, W. (1968). "Das Forteben des gotischen Rechtes in Sudfrankreich und Katalonien". Album J. Balon. Bruselas. UdrNA, F. (1974). "El sedimento visigodo en la Cataluña condalw. Revista de Architos, Bibliotecas y Museos. Madrid. LXXVII-2 p. 565-581. ZimmermanN, M. (1973). "L'usage du droit wisigothique en Catalogne du IX au XII siècle. Approches d'une signification culturelles. Mélanges de la Casa de Velazquez, Madrid, IX, p. 233-281. Con explícita referencia al testamento véase el artículo de BASTIER citado en la nota 2.

5. GARCIA, H. (1955), «La forma del testamento en la España visigóticas. Estudios históricos y documentos de los Arehivos de Protocolos. Barcelona: III, p. 215-228. PERez DE BENAVIDES, M. (1975). El testamento visigótico. Una contribución al estudio del derecho romano vulgar. Granada. Son quienes mejor lo han estudiado.

6. Lex V-2-14 y Lex V-2-12, respectivamente. 
mento. Así nace la publicación, si se trata de un testamento escrito, la adveración, si aquel es oral. Las dos formas aparecen en los documentos medievales estudiados.

La procedencia visigoda de estas formas testamentarias aparece con mayor claridad frecuentemente cuando se cita, con mayor o menor exactitud y extensión, una de las dos leyes mencionadas. Así, una primera cuantificación nos permite observar citas explícitas referidas al Liber en una cuarta parte de los documentos analizados, de ellas el $75 \%$ se refieren a la cuarta forma testamentaria, la oral, y el $25 \%$ restante a las formas escritas. Hay que observar, no obstante, que en la mayoría de casos no hay una referencia textual a la ley $y$, que como veremos, la mayoría de los documentos reflejan publicaciones de un testamento escrito.

\section{La muestra documental}

Sobre un total de 1.280 testamentos de los siglos X, XI y XII, 500 revisten la forma de adveración o publicación sacramental, de ellos 78 corresponden a otros tantos testamentos conservados. En general se trata de dos documentos distintos, aunque de forma excepcional encontramos algún caso en que en un mismo pergamino consta el testamento y su publicación sacramental hecha por los testigos con las formalidades requeridas?.

Respecto a la estructura documental y sin pretender realizar un exhaustivo análisis diplomático, podemos seńalar tres partes bien diferenciadas: la inicial, en que se introduce el documento a través de una fórmula estereotipada; la central, donde constan detalladas las disposiciones testamentarias y la parte final, donde a menudo constan las circunstancias de la muerte y la declaración jurada de los testigos, así como el escatocolo con la fecha y las correspondientes subscripciones. En apéndice ofrecemos tres modelos documentales de la primera y tercera parte citadas.

La fórmula inicial deja constancia de la celebración del juramento sobre la voluntad del testador fallecido; esta fórmula varía algo con el transcurso del tiempo, factor que deberemos tener en cuenta a lo largo de todas nuestras conclusiones. La más generalizada hasta mitad del siglo XI es la que empieza así: "Conditiones sacramentorum ad quarum residebat...., recogida en el manuscrito de Ripoll, número 74, y que reproducimos, sacada de la documentación estudiada, en apéndice como modelo.

A partir de la segunda mitad del siglo XI observamos cómo se introduce progresivamente una nueva fórmula mayoritaria: «Hec sunt conditiones sacramentorum ultime voluntatis cuiusdam hominis...», que acabará por imponerse en el siglo XII, mientras desaparecerá la anterior. Es interesante especificar el sentido que puede tener este cambio de la fórmula inicial. En la primera fórmula, cro-

7. Caso de Belisindis, ACV cal. 6 Ep. II-65 t O73-IV-26); del canónigo Borrell Adroer, ACV Liber dotationum, f. 55 (1093-V-10); de María, ACV cal. 6, p. 2234 (1110-I-11) y de Bonet de Deu, ADB publ. por Alturo, ]. Liarxiu de Santa Anna... doc. 280 (1152-X-27). 
nológicamente hablando, se alude inicialmente al tribunal ante el cual se presta el juramento, mientras que en la segunda es el testador o, mejor, es su voluntad testamentaria la que es subrayada de forma especial ${ }^{8}$. El tribunal muchas veces se reducirá a la figura del juez y en algunos casos será citado al final del documento, inmediatamente antes del escatocolo e incluso ni siquiera será mencionado expresamente, sino que solamente figura en las subscripciones del documento?

A continuación generalmente se mencionan los testigos, en número de dos o tres y el altar y la iglesia en donde se realiza la ceremonia y se presta el juramento. Hemos contabilizado más de 200 lugares distintos: castillos, catedrales, parroquias. A partir de finales del siglo XI y sobre todo en el XII se generaliza realizar las publicaciones sacramentales en el altar de san Félix en la iglesia barcelonesa de los santos Justo y Pastor. En Gerona es el altar de sant Anastasi en su catedral el más utilizado al respecto. El documento contiene a menudo el nombre de los albaceas. Los testigos juran haber visto y oído que el testador hizo su testamento por escrito dictándolo u oralmente con indicación de la causa que en la mayoría de los casos es la enfermedad, aunque también motiva la redacción del testamento la marcha en peregrinación a Santiago de Compostela, Jerusalén, Roma o algún otro lugar ${ }^{10}$, o bien una expedición a Hispania para luchar contra los musulmanes, como es el caso de diversos testamentos otorgados con motivo de la expedición a Córdoba del año $1010^{11}$ o el de Bernat Ramon, caballero, que hace testamento oral, que conocemos por su posterior adveración adum in exercitum Berengarii Raimundi comitis pergens...s ${ }^{12}$.

A continuación se transcribe el testamento que en los casos ya citados en que lo conservamos aparte de la publicación vemos que coincide, con excepción de algún caso en que la publicación corresponde a un testamento posterior. Como hemos advertido en el presente trabajo no nos ocuparemos de los mecanismos sucesorios de los cuales tratamos hasta inicios del siglo Xl en nuestra obra ya citada $\mathbf{a}^{13}$.

8. Ver apéndice $\mathrm{n} .1$ y 2 , respectivamente.

9. Ver apéndice n. 3, el primer caso. Ejemplos en que figura únicamente la subscripeión del juez: BC, p. 9084 (1056-VII-21); ACB. LA-III doc. 17 (1082-VIII-17); ACV L. dot. f. 50-51 (1101-III-16).

10. A Jerusalén: Seniofred (1042-1-27) ACU, LD, 445. P.Baraut, 544, Arnau, obispo de Barcelona (1143-XI-6) ACB LA.I-642. A Santiago de Compostela: Teobald, canónigo de Vic (1055-II-17) ACV Ep. II-54, Vidiá (1145-VI-10) ACA CSC, 136. Publ. RuUs, J. (1947). El Cartulario de San Cugat del Valles. Barcelona, doc. 964. A Roma: Guillem, arcediano de Vic (1051-VII-25) ACU, p. 727. BARAUT, P. Els documents de la catedral de la Seu d'Urgell. "Urgelliaw, doc. 643. Bernat Ramón, cavaller (1073-IX-28) BC p. 4006.

11. Ver sus publicaciones sacramentales en: UDINA, A. La successio testada..., doc. 82,83 , 84,88 .

12. Ver la regesta del documento en Pasqual, Sacrae Antiquitatis Cachaloniae Monumenta, III, f. 200. Ms. 729 Biblioteca de Cataluna. Otros ejemplos de testamentos otorgados al ir a guerrear: (1156-IX-28) el noble Ramon Arnau ACA, OR. Gran Priorato, perg. 266; o el caballero Ramon Guitart (1048-VII-25) ACU. p. 393. LD. 767, BARAuT, P. Els documents..., doc. 619 .

13. Ver nota 3. 
La parte final del documento recoge la fecha, normalmente el mes, de la muerte del testador y el juramento explícito de los testigos en términos como los que reproducimos en el documento modelo del apéndice ${ }^{14}$, con indicación, a menudo, del término legal de los seis meses, plazo máximo para proceder a la adveración o publicación del testamento. La fecha y las subscripciones de testigos, albaceas, juez y escribano cierran el documento.

Noventa de las recepciones sacramentales estudiadas corresponden a la formulación de un testamento oral, cuarta de las formas recogidas en la ley visigoda, en este caso se alude con frecuencia al Liber Fudiciorum en términos semejantes a éste: «In goticarum leges sanctionem ita cautum habetur ut voluntas defuncti iuxta modus quarti ordinis firmissimum roborem obtineat si testes ipsi qui hoc audierint et rogati ab ipso conditore extiterint hoc quod iniunctum habuerint infra sex mensium spacium sua coram iudice iuratione confirmarent...n. En otros casos la fidelidad a la Lex es prácticamente total como puede verse en la introducción a la adveración sacramental del noble Guerau Alemany de Cervelló: «In goticis legibus reperitur scripturam ut voluntas defuncti, iusta modum quarti ordinis edita, firmissimum robur obtineat, si testes ipsi, qui audierint et rogati et conditore extiterint, hec quod iniunctum habuerint, infra sex mensium suam coram iudice iuracione confirment, ex denique iuramenti condicione, tam sua, quam testium manu corroborent, et sic voluntas defuncti habeat firmitatem.... ${ }^{15}$. Hay que destacar que las citas referidas a la ley visigoda aumentan notablemente desde la segunda mitad del siglo XI hasta finales del siglo XII y que son especialmente numerosas las que se refieren al testamento oral, lógicamente el que necesitaba un soporte legal más evidente.

\section{Requisitos legales}

Acabamos de ver como en algunos documentos al citarse de forma más o menos textual el correspondiente artículo del Liber Iudiciorum aplicable, se recogen los requisitos esenciales que debía tener la publicación o adveración sacramental y que cran esencialmente idénticos tanto si se trataba de testamento escrito como oral, si bien en este último caso, como acabamos de señalar, era más frecuente el recurso directo a la cita de la ley.

Intentaremos analizar hasta que punto se cumplen en los documentos estudiados estos requisitos. En síntesis y recordando lo dicho ya, los testigos deben prestar juramento ante el juez y el sacerdote de la voluntad testamentaria del difunto en un plazo máximo de seis meses a contar desde la fecha de la muerte del testador.

La presencia de testigos se da siempre en los casos examinados. Muy frecuentemente $y$, en especial cuando se trata de la adveración de un testamento

14. Ver apéndice, doc. 3.

15. Adveración de Ermengol Lobató en ACB LA - III, 170 (1076-X-30) y la de Guerau Alemany en ACA CSC publ. por Rius, El Cartulario de San Cugat..., doc. 906 (1130-XII-15). 
oral, los testigos son los propios albaceas. Su relación con el testador puede ser de parentesco, más frecuente cuando se trata solamente de los albaceas, o de amistad. Su número oscila entre 2 y 7 , aunque lo más corriente es que sean 2 o 3. En algunos casos nos encontramos con personajes laicos o eclesiásticos de significación política y social: el abad de Sant Llorenç del Munt en la publicación del testamento del levita Guillem; el obispo de Gerona y el conde de Barcelona en la del canónigo de Gerona Guifré Guillem o el conde Guifré de Cerdanya y el vizconde Seniofredo en la de la condesa Guisla ${ }^{16}$.

En cuanto al tribunal receptor del juramento, constatamos una evolución a partir de la segunda mitad del siglo XI. Hasta este momento la presencia de un juez, excepcionalmente dos o tres y de uno o dos sacerdotes es lo más corriente. Después tienden a desaparecer los sacerdotes y permanece el juez, uno siempre, que no olvidemos que era también sacerdote; ahora bien, al final del período estudiado nos encontramos con cierta frecuencia con la presencia del veguer del juez y en un caso significativo de la evolución de las instituciones privadas sucesorias con la del notario público de Vic, el canónigo Pere d'Ayreis $^{17}$. A destacar el interés que las menciones de los jueces tienen para una elaboración de listas de los distintos jueces de los condados catalanes en los siglos $\mathrm{X}, \mathrm{XI} \mathrm{i}$ XII, punto de partida para el estudio de esta institución de singular importancia como hace años señaló Pierre Bonnassie ${ }^{18}$. Efectivamente encontramos en los documentos analizados jueces bien conocidos como los de la familia Marc: Ervigi, Bofill i Guillem en Barcelona, al lado de otros menos conocidos como Guillem, Ricard o Pere en Vic; Sendred, Guisad o Guillem en Urgel; Bernat Guifré en Gerona.

El término legal para proceder al juramento sobre la voluntad testamentaria exigido, como vimos al principio, en la ley visigoda era de seis meses. En los casos estudiados vemos como con mucha frecuencia en la parte final del documento se especifica el mes de la muerte del testador y también se añade la constancia de la publicación del testamento dentro de los seis meses preceptuados por la ley. En efecto, el término que hay entre la muerte del testador y la publicación sacramental de su testamento oscila entre unos días - con algún caso excepcional en que la publicación se hace el mismo dia - y los cinco meses largos; con todo, hemos podido encontrar algunos casos aislados en los que el término se incumple, en los cuales casi siempre se hacen constar las causas que lo justifican. Así, por ejemplo, los testigos que prestan juramento sobre el testamento de Berenguer de Vallvidrera señalan la imposibilidad de haber realizado dicha publicación dentro del término legal; de hecho pasan 19 días de los seis meses fijados; la causa aludida es la conducta fraudulenta de Pere de Badalona, que tenía escondido el testamento. En la publicación

16. ACA OR S. Llorenç del Munt, p. 128 (1040-V-1); VILLANUEVA, Viage literario a las Iglesias de España. XII doc, 29 (1065-X-10) y MARCA, P. de. Marca Hispánica. doc. 184, respectivamente.

17. ACV cal. 6 p. 2792 (1200-VI-1).

18. Catalinya mil anys enrera. Barcelona, 1979, vol. I, p. 163 y ss. 
del de Pere d'Oló se justifica haberse sobrepasado los seis meses de la forma siguiente: "si nos predicti testes hanc ordinationem predicti testatoris tantum distulimus corroborare et ultra terminium quo deberet promulgari tam fere duo anni elapsi sunt hoc impedimentum interfuit quod ego Berengarius de Olone per longum tempus steti in curia comitis urgellensis et ego Arnaldus de Togores steti per longum tempus in obstatico et ideo non potui corroborari infra tempus quo lex precipit. Unum quamvis tempus transactum sit mandato domini regis qui hec omnia novit et voluit quod voluntatem istius testatoris nos publicaremur...... Otro caso ilustrativo es el de la publicación testamentaria de Ramón de Guardia en que se alude a la negligencia de los albaceas y a la ignorancia de los testigos; la ausencia del requisito que invalidaría el testamento se suple por mandato regio, mandato que encontramos claramente expresado en la publicación del testamento de Guillem de Bedorch en el cual significativamente no consta que existiese juramento y Pere de Corró, veguer del juez Ramón y el mismo juez dicen: acorroboramus auctoritate incliti Ildefonsi, dei gratia regis Aragonensis, comitis Barchinonensis et marchionis Provinciae, quia quod principi placuit legis habet vigorem, atque ex hoc aliter suam voluntatem non mutavit nobis scientibus..... Semejante cláusula da validez a otra publicación, la del testamento de Bernat de Gelida, referida al rey Pedro el Católico ${ }^{19}$. Hay que destacar que el incumplimiento del término legal de los seis meses se da especialmente, siempre como caso excepcional y minoritario, al final del periodo estudiado, en que las adveraciones sacramentales se rarifican cada vez más. Ello es muestra, por un lado, de la progresiva desaparición del derecho visigodo y por otro del influjo del derecho común, fortalecedor de la monarquía, y que vemos claramente reflejado en el principio romano sobre el poder del rey: "quia quod principi placuit legis habet vigorem...,. Además del caso citado de Pere de Bedorch, hemos constatado algún otro caso en que se incumple el término sin que se justifique ${ }^{20}$.

\section{Las circunstancias de la muerte del testador}

Es, sin lugar a dudas, una de las informaciones más preciosas que nos suministran las publicaciones sacramentales de testamentos. En la mayoría de casos la causa de muerte es la enfermedad que precisamente ocasionó el acto testamentario: así cuando se explica el cómo y el porqué del testamento muy a menudo se usa un formulismo kiacens in egritudine unde obiít..."; íncluso en los casos en que no consta explícitamente la causa de la muerte es lícito pensar que se trata de muerte natural. Excepcionalmente se indica el tipo de enfer-

19. ACA CSC publ. por Rrus, J. El Cartulario de San Cugat... doc. 983 (1150-II-23). ACB p. 1-5-490 (1189-VI-25). ACA C. p. Alfons I, 634 (1192-IX-22). ACA CSC publ. por Ruus, J. El Cartulario de San Cugat... doc. 1186 (1192-1-9) y ACA CSC publ. por Rrus, J. El Cartulario de San Cugat... doc. 1219 (1197-III-19).

20. Caso de la publicación del testamento del levita Juan ACB LA I, doc. 348 (1036-XII-7). hecha casi nueve meses después de su muerte. 
medad que ha ocasionado la muerte: caso, por ejemplo, de Bofill Donuci que al volver de peregrinar al Santo Sepulcro murió en Antioquia «de infirmitatis corporis sui quam dissinteriam vocant...., la misma enfermedad que provoca la muerte a Teobaldo, canónigo de Vic; Pere Miró murió «ex hydropico morbon y en el caso de Berenguer Isarn cabe resaltar el detalle de las circunstancias de su muerte: «deinde cum fleobotomatus esset in domo sua in aggerensi castro dum nocte vellet redire ad cameram per gradus cecidit in terram et debilitato cruore per aliquot dies graviter egrotavib" ${ }^{21}$. Tenemos asimismo constancia de intervenciones médicas que no evitaron, sin embargo, la muerte: así Teobaldo murió cuatro días después que «invalescente gravi dolore ab vulneribus a medico quodam incisus et adhustus fuerit... y el canónigo de Vic Guillem Cixela enfermó camino de Roma y fue tratado por médicos florentinos $\sin$ éxito $^{22}$.

En algún caso excepcional se nos dan detalles previos al otorgamiento del testamento hecho por enfermedad, como ocurre con Guillem Ramón, abad de Ager y canónigo de Vic, del cual se explica que hallándose en tierras de Osona durante ocho días, había pernoctado en los castillos de Casserres y Corcó, celebrado una reunión con el obispo de Vic y el vizconde de Cabrera, y en el monasterio de Santa Maria de l'Estany enfermó, ratificó un testamento anterior al cual añadió algunas mandas y murió t3 $^{23}$. También hay constancia en ocasiones de haberse superado la enfermedad que causó el testamento: el caso de Seniulf Guillem que vivió "per longa spacia dierum..." después de hacer el testamento ${ }^{24}$.

En otros casos la muerte sobreviene durante una peregrinación; hemos de suponer por causas naturales, que como hemos visto era una de las causas de testar. Además del ya citado caso de Guillem Cixela, podemos señalar de entre otros el del canónigo de la Seu d'Urgell, Isarn; el también canónigo de Vic, Riculf Eldemar; Berenguer Guillem, que murió en Aquapendenta al regresar de Roma, o Berenguer Bofill que eperrexit Iherosolimam et completa peregrinacione sua obiit in prefata urbe...n. Interesante reseriar aquí la referencia a que la peregrinación se había realizado ${ }^{25}$.

En una sociedad catalana feudal y fronteriza con el mundo musulmán no debe sorprendernos que la muerte sea consecuencia de heridas recibidas en

21. Ver respectivamente: ACG p. 77 (1067-XI-27); ACV Ep. II, p. 54 (1055-II-17). ACU p. 579, BARAUT, P. Els documents... doc. 905. (1076- III-18) y ACA OR Gran Priorat, p. 263 (1093-III-5).

22. El primer documento publicado por BARAuT, P. Els documents... doc. 1048 (1088-IV-7) y el segundo inédito en ACV Ep. II-p. 61 (1061-VI-13).

23. ACV cal 6. p. 2195 (1082-XI-12).

24. (1061-V-27), publicada por ALTURO, J. (1985). L'Arxin antic de Santa Anna de Barcelona del 942 al 1200. Barcelona. Vol. II, doc. 78.

25. El primero publicado por BARAUT, C. Els documents... doc. 816 (1068-VIII-10), el segundo inédito en ACV Liber dotationam, f. 66. (1062-XII-24), el tercero en ACA C.p. Ramon Berenguer I, 475. (1075-VI-20) y el cuarto en ACA CSC. f. 136, RIUS, El Cartulario... doc. 890 . 
disputas y batallas. Ermengol d'Oló murió en un enfrentamiento con sus primos que se nos narra así: «vocatus est ad placitum per suos proprios consanguineos... et in ipsa invitacione placiti dolose deceptus gravi periculo immenente et casu mortis interveniente, ibi crudeliter vulneratus atque lanceis vulneratus subito in ipso placito ex hoc migravit seculo in mense preterito augusto...». El caballero Bernat Ramon murió a manos de los sarracenos así como Pere Palau además de otros que no citamos en ara a la brevedad ${ }^{26}$.

La referencia al lugar de la muerte, aparte de los casos ya mencionados de peregrinación figura solamente en algunas ocasiones. Hemos de suponer que normalmente era la casa del testador cuando se trata de muerte natural, la mayoría de casos como ya hemos dicho; algunas veces se precisa más: así la vizcondesa Riquildis murió, según consta en la publicación sacramental de su testamento, que es una de las más antiguas, en su torre de Narbona: la noble Disposia murió en su castillo de Cornellá en tierras gerundenses; la condesa Ermessenda, en una casa junto a la iglesia de San Quirze de Besora; Belisindis, en el castillo de Cassá ${ }^{27}$. En otros documentos se cita la casa de algún pariente o amigo: el obispo de Gerona Bernat Bernat murió en casa de Dalmau Gausbert; Guifré de Mata, en la de su hermano Riculf; Bernat Guerau, en la de su hermano Ponç i Dalmau Vidal, en la del clérigo Juliá ${ }^{28}$. La muerte en el mar, durante el viaje de regreso de peregrinaciones sobrevino al sacerdote Guifré Guillem que «rediens a partibus Apulie cum domno Berengario gerundense episcopo seniore meo, iacens in ipsa navis superposita mari que rustico nomine dicitur catus, detentus ab egritudine... y también a Bernat que volviendo de San Miguel del Montegargano "in nave vitam finivito ${ }^{29}$.

El dato de la fecha de la muerte que, como se ha dicho, figura como prueba del cumplimiento del requisito de los seis meses, nos ha permitido cuantificar por meses la fecha de la muerte de los distintos testadores. Los meses de octubre y marzo, con 40 y 39 casos respectivamente, son los de mayor mortandad, mientras que junio y julio, con 19 y 22, presentan la menor mortandad. Una agrupación por cuatrimestres nos da los resultados siguientes:

$$
\text { Enero-Abril }=132 \quad \text { Mayo-Agosto }=98 \quad \text { Setiembre-diciembre }=134
$$

La influencia del clima estacional parece bastante clara, si tenemos en cuenta que la inmensa mayoría de muertes se producen, como hemos señalado, por causas naturales.

26. Ver nota 8 y (1135-VI-9) ACA C.p. Ramón Berenguer IV, 46, respectivamente.

27. Ver respectivamente JUNYENT, E. (1982). Diplomatari de la eatedral de Vic. Vie: doc. 346 (962-V-23). ACA C.p. Ramón Berenguer III, 39 (1096-VIII-31). MiquFL, F. (1945). Liber Feudorum Maior. Barcelona: doc. 483, (1058-III-8) y ACV cal. 6 ep. II p. 65.

28. ADG Cartulari de Carlemany, f. 323 (1075-I-31); ACV cal. 6 p. 1407; (1049-I-5); ACB LA-IV, doc. 47 (1065-VIII-21) y ADG Cartulari de Carlemany, f. 373 (1089-IX-22).

29. ADG, Cartulari de Carlemany, f. 274 (1080-XI-4). ACU BARAUT, P. Els documents... doc. 1089 (1092-III-28). 


\section{Conclusiones}

La forma de la publicación sacramental del testamento aparece en Cataluña a mediados del siglo $\mathrm{x}$ y tiene vigencia hasta el siglo XIII en lo que se refiere a su transcripción documental. Es más frecuente su utilización en el siglo XI que en el x o el XII y principios del XIII. La terminología más adecuada para designar este documento de aplicación del derecho es de adveración sacramental del testamento.

La evolución cronológica es además perceptible en el papel preponderante que adquieren los testigos a partir de mediados del siglo XI y que eclipsa el del tribunal originariamente más importante.

La fidelidad a los requisitos señalados por la ley visigoda es muy notable hasta finales del siglo XII en que se observan síntomas de cambio significativos.

Este tipo documental permite aproximarnos a aspectos dificilmente investigables de otra forma como los referidos a las circunstancias de la muerte de interés para la historia de la medicina de este período tan difícil de realizar y de la vida cotidiana en general.

$\begin{array}{ll}\text { Abreviaturas utilizadas } \\ \text { ACA } & \text { Archivo de la Corona de Aragón } \\ \text { ACA C.p. } & \text { Archivo de la Corona de Aragón, Cancilleria, pergaminos } \\ \text { ACA OR p. } & \text { Archivo de la Corona de Aragón, Ordenes religiosas, pergaminos } \\ \text { ACB LA } & \text { Archivo Capitular de Barcelona, Libri Antiquitatum } \\ \text { ACB, p. } & \text { Archivo Capitular de Barcelona, pergaminos } \\ \text { ACV cal. 6 p. } & \text { ACB calaix 6, pergamino } \\ \text { ACV Ep. p. } & \text { ACV Episcopologi, pergamino } \\ \text { ADG } & \text { Archivo Diocesano de Gerona } \\ \text { BC p. } & \text { Biblioteca de Cataluña, pergamino } \\ \text { CSC } & \text { Cartulario de San Cugat del Vallés } \\ \text { doc. } & \text { documento } \\ \text { f. } & \text { folio } \\ \text { p. } & \text { páginas } \\ \text { Publ. } & \text { publicado } \\ \text { vol. } & \text { volumen }\end{array}$




\section{Apéndice documental}

1. Parte inicial y final de la publicación sacramental del testamento de Cristiá. 1013 diciembre 19.

ACA C.p. Ramon Borrell, 107. Publ. por UDINA, A. (1984). La successió testada a La Catalunya altomedieval. Barcelona, doc. 96.

Conditiones sacramentorum ad quarum exordinatione Geribertus sacer et Bonushono, levita qui et iudice, et in presentia Vivane, presbitero, Galindoni, levita... et aliorum multorum bonorum hominun qui ibidem aderant, testificant testes prolati quas proferunt, id est, [siguen los nombres...] in faciem de supradicto sacerdote vel iudice ad comprobandan causam elemosinariam de condam homo nomine Xristiano. Et hec sunt nomina testium qui hoc testificant sicuti et iurant: Riculfus, Sclua et Bonefilius exarator, iurandi autem dicimus in primis per Deu Patrem Omnipotentem et per Ihesum Christum, filium eius, Sanctumque Spiritum, qui est in Trinitate unus et verus Deus, et per hunc locum venerationis Sancta Dei genetrix Maria, cuius baselica sita est extra muros civitatis Barchinone, in locum ubi dicunt ab ipso Pino, ex quorum latere dedicatum extra altarium nomine Sancti Pancrasii martiris Domini, supra cuius sacrosancto altario has condiciones manibus nostris continemus vel iurando contangimus, quia nos suprascripti testes scimus bene in veritate sapemus, de presente eramus occulis nostris vidimus et aures nostras audivimus ad ea ora quando iacebat condam Xristianus in sua egritudine unde obiit, sic nos videntes et audientes comendavit vel iniunxit omnen suam elemosinam ad istos suos predictos elemosinarios, et precepit eis ut si de ipsa egritudine mortuus fuisset, sicut et fuit, plenam potestatem habuissent ad distribuere omnem facultatem suam quemadmodum eis hordinavit in suum testamentum... [sigue el contenido de disposiciones testamentarias].

Et cum hec omnia hordinavit adhuc loquela plena et memoria integra sic migravit de hoc seculo in mense isto decimbrio in qua hodie sumus. Et ea que scimus recte et veraciter testificamus atque iuramus per superadnixun iuramentum in Domino. $\mathrm{Et}$ nos elemosinarii sic iuramus in Deum et propter Deum quia quantum isti hic testifi caverunt in isto iuditio verum est et nulla fraus nec ullo malo ingenio hic impressa non est, sed secundum voluntatem ipsius conditoris est factus vel editus. Late condiciones... [figura la fecha y las subscripciones de testigos, albaceas y del juez y sacerdote integrantes del tribunal que recibe el juramento...].

2. Parte inicial y final de la publicación sacramental del testamento de Bernat Gelmir. 1054 octubre 11.

Archivo Capitular de Barcelona. Diversorum p. 1-4-185.

Condiciones sacramentorum ultime voluntatis cuiusdam hominis nomine Bernadus Gelmiri verbis tantumodo ordinatam quod intercidente casu incurie scribere non licuit nec voluit testamentum, set in tabula lignea verbis quod ordinavit scribere iussit et manu propria solito signo litteris firmavit ibi precipiens mandavit ut quandocumque illi mors advenisset ante quam testamentum fecisset potestatem habuiset sui helemosinari distribuendi omnibus rebus suis sicut precepit eis coram testibus subterius anotati, et precipiens ut sui fuissent tutores et helemosinarii, id est, Gislibertum, pontificem qui est vicecomes, et Guielmus Guifredi episcopus ausonensis qui tunc erat archile- 
vita, Gondeballum Bisorensi et Remundum Borrelli et Ermengaudus Orucii et Guilabertum Marcucium et Compannus Marcucii et Aiganem, uxorem suam et Gerallum, levitam, filium suum et Guitardus Orpini. Et nomina vero testium qui hoc testificant sicuti et iurant, id est Petrus, clericus et Ellemarus, sacer et Gerallus Compannus et Bonucius, presbiter et Ihoanes [sic] nutritus. Nos vero prescripti testes, id est Ellemarus, sacer et Gerallus Compannus unum damus testimonium iurandi autem dicimus primo per Deum Patrem Omnipotentem et per Ihesum Christum filium eius Sanctumque Spiritum confitentes hac Trinitatem unum et verum super altare consecratum in honore Domini et Sancti Pastoris qui est situs in ecclessia Sancti Iusti infra moenia urbis Barchinona supra cuius sacrosancto altario has condiciones manus nostras continemus et iurando contangimus quia nos prescripti testes ben scimus videndo et audiendo quando prescriptus Bernadus qui fuit condam ordinavit suam ultimam voluntatem et precipiens predicte uxore sue Aigane et Gerallo filio suo et Gislibertus Marcucii et Ermengaudus Orucii ut distributores fuissent suarum rerum sicut in hac condicione de ipsa tabula lignea prescripta est translatum fideliter et absque ulla diminutione...

[Constan a continuación las disposiciones testamentarias del testador].

... Et a prescripto die et anno vixit predictus conditor usque dum ordinavit prescriptis verbis, quinque annis et meses III et quindecim die, et ordinavit prescriptis verbis ad Aiganem prescriptam et ad Guilabertum Marcucium et Gerallum filium suum, et postea supervixit XI diebus et sic fuit mortuus idus Maii anno XXIII regni prescripti regis.

Late condiciones in Domino V idus octobris anno XXIII regni Henrici regis. S+num Aiganem feminam. S+num Guilabertum Marchucii.

S+num Geralli levita et sacrista hec sunt tutores et helemosinari, quibus prescriptis verbis inuncti fuerunt et omnia corroborari atque firmari per Deum verum et istarum sanctarum reliquiarum. S†num Gerallus Compannus. S†num Ermengaudus Aiulfi; nos testes sumus et hos verbis comendari vidimus Bernardi prescripti conditori in potestate Aiganem et Guilaberti et Geralli, in suo sensu et memoria integra et loquela, per Deumn Patrem Omnipotentem et istarun sanctarum reliquiarum. S+num Gerallus Compann. S+num Ellemar, sacer; hec sunt testes Geralus et Ellemarus sacer quibus presentibus Bernadus prescriptis conditor instiuit et scribere iussit in tabula lignea prescriptam voluntaten et manu popria firmavit cum literis suis, et postea mutavit hoc quod suprascriptum est in suis verbis. $S_{+}$num Ermengaudus. $S_{+}$num Compannus levita. S+num Reimundi levita. S+num Bernadi. S+num Guielmi presbiter, $S+$ num Guielmi iudex.

S+num Bellihominis cognomento Gerallus levita, cum literis fusas in variis locis in sex locis et superpositis in tribus locis et subscripsit die et anno prefixa.

3. Parte inicial y final de la publicación sacramental del testamento de Bernat de Gelida. 1197-111-19.

ACA CSC f. 184, doc. 589. Publ. RuUs, J. (1947). El Cartulario de San Cugat del Vallés. Barcelona, doc. 1219.

Imuramus nos restes scilicet Petrus Rumeus et Berengarius de Gelida, per Deum vivum et verum super altare sancti Felicis martiris, quod est constructum in ecclesia beatorum 
martirum Iusti et Pastoris, infra meniu urbis Barchinone, supra cuius sacrosancto altari has condiciones quia vidimus et presentes adfuimus quando Bernardo de Gelida, iacens in magna egritudine et sperans in misericordia Dei, et fecit suum testamentun... [sigue la designación de albaceas y la enumeración de las diferentes mandas testamentarias...].

... et obiit ab hoc seculo eodem mense et anno [agosto de 1197]. Hanc igitur Petro de Corrone, barchinonensi scriptore, vicario Raimundi iudicis et aliis testibus presentibus, veram esse fideliter corroboramus auctoritate et mandato incliti Petri regis...

Late condiciones XIII kalendas aprili anno Domini MCXCV. [El documento acaba con las suscripciones de testigos, juez y del rey]. 